\title{
Nanoparticles and their Biomedical Applications
}

\author{
Oluwafemi Adeleke Ojo ${ }^{1,2, *(\mathbb{D})}$, Israel Idowu Olayide ${ }^{2}(\mathbb{D})$, Maureen Chidinma Akalabu ${ }^{2}$, Basiru Olaitan \\ Ajiboye $^{2(D)}$, Adebola Busola Ojo ${ }^{3(D)}$, Babatunji Emmanuel Oyinloye ${ }^{2,4}$, Murugan Ramalingam 5 (D) \\ Department of Biochemistry, Landmark University, Omu-Aran, Nigeria \\ Department of Biochemistry, Afe Babalola University, Ado-Ekiti, Nigeria \\ Department of Biochemistry, Ekiti State University, Ado-Ekiti, Nigeria \\ 4 Biotechnology and Structural Biology (BSB) Group, Department of Biochemistry and Microbiology, University of \\ Zululand, KwaDlangezwa 3886, South Africa \\ 5 Biomaterials and stem cell engineering lab, Centre for Biomaterials, Cellular and Molecular Theranostics, School of \\ Mechanical Engineering, Vellore Institute of Technology (VIT) (Deemed to be University), Vellore 632014, India \\ * Correspondence: oluwafemiadeleke081@gmail.com;
}

Received: 30.06.2020; Revised: 24.07.2020; Accepted: 26.07.2020; Published: 28.07.2020

\begin{abstract}
Over the years, due to the remarkable functional properties, the nanoparticles have been widely used and being tested in the treatment and diagnosis of diseases such as cancer, diabetes, etc. The green synthesis of these nanoparticles can be achieved by physical, chemical, and biological methods. Nanoparticles biosynthesis is put forth to be advantageous over chemical and physical methods because it is non or minimally toxic, environmentally friendly, and cost-effective. A green biosynthesis is an approach that connects nanotechnology with plants, microorganisms, waste materials, and biomolecules. The biological methods help to eliminate destructive processing situations, via letting the synthesis at biological $\mathrm{pH}$, room temperature, and simultaneously, affordable price. Among various biological alternatives, medicinal plants and plant extracts seem to be the best options. Plants are the chemical factories of nature, the plant extracts contain various secondary metabolites, and it functions as reducing and stabilizing (capping) agent in bio-reduction reaction to synthesize new nanoparticles. Keeping these points in view, the present article reviews the various synthesis methodologies, key factors, characterizations, usages, and foretold antimicrobial approach in a systematic manner, concentrating on several green pathways for nanoparticles synthesis.
\end{abstract}

Keywords: Nanoparticles; plants; material processing; toxicity; biomedical application.

(C) 2020 by the authors. This article is an open-access article distributed under the terms and conditions of the Creative Commons Attribution (CC BY) license (https://creativecommons.org/licenses/by/4.0/).

\section{Introduction}

An element with proportions reads in nanometers $(\mathrm{nm})$, which is equivalent to one billionth of a meter, is said to be a nanoparticle that occurs naturally and/or produced via human actions [1]. These nanoparticles have large surface areas resulting from their very small sizes, which readily makes them take part in their work. That is why most of the acting ingredients of plant extract or animal serum occur in nanoscale. Because they are minute to be seen with a microscope, they have exceptional material features, with effective uses in a variety of areas, such as medicine, engineering, catalysis, and environmental remediation. With the progression in nanotechnology, a great number of nanomaterials i showing with exclusive properties, displaying a range of applications [2]. The extraordinary features of nanoparticles have made them relevant in numerous biomedical and therapeutic approaches [3]. Bearing in mind the shortcomings of physio-chemical approaches, cost-effective and energy effective novel 
substitute for nanoparticles biosynthesis by means of microorganisms, medicinal plant, and natural polymers as reducing and capping agents are developing really fast. The current review sums up the synthetic protocol, parameters, characterizations, applications and anticipated antimicrobial approach in a methodical way, concentrating on several green pathways for synthesis.

\section{Properties of nanoparticles}

There are some general properties of nanoparticles; it is somewhat difficult to give a unifying answer. Physically, the electronic structure of nanoparticles may be distinct from the bulk. In bulk materials, the electronic state is ongoing. Moreover, because of size, the electronic state of nanoparticles may be discontinuous. This means that the aggregated surface area of the material is greater than the relating bulk materials with the same mass. This leads to much higher chemical activity because most of the chemical reactions happen on the surface. Some applications of nanoparticles depend on their sizes (e.g., suspension in a liquid or penetrating certain biological membranes) [4].

\subsection{Toxicity of nanoparticles.}

Nanoparticles toxicity is termed nanotoxicity. Nanotoxicology is defined as the toxicity of nanoparticles and nanomaterials. The subdivision of nanoscience that studies the use of toxicity of nanoparticles is nanotoxicology. Nanotoxicological studies are planned to ascertain the level at which these properties might constitute an assault to the atmosphere, animals, and humans. For example, nanoparticles are known to cause damage of the central nervous system, circulatory system, respiratory system, and cardiovascular system in a model Fig 1.

\subsection{Classification of nanoparticles.}

The classification of nanoparticles depends basically on the number of dimensions that lie within the nanometer range [5]. Nanoparticles are classified into two main types; organic and inorganic nanoparticles. Organic nanoparticles comprise; lipid nanoparticles: (micelle, liposome, and nanocapsule), dendrimer, hybrid, nanosphere, compact polymeric and nanocapsule and the inorganic nanoparticles; fullerene, quantum dot, some metallic nanoparticles (Silica (Silicon metal), Palladium (Pd), Silver (Ag), Lead (Pb), Gold ( $\mathrm{Au}$ ), Platinum (Pt), Ruthenium ( $\mathrm{Ru})$, copper $(\mathrm{Cu})$, etc.) [6].

Micelles are lipid molecules that arrange themselves spherically in an aqueous solution. While micelles form, they respond to the amphipathic nature of fatty acids (polymers of lipid), which means that they have both the hydrophobic end and the hydrophilic end. The main reason for this spherical formation is because of the hydrophobic interactions the molecules experience, on exposure to aqueous surroundings. When the hydrophobic tails are not separated from water, this leads to the water forming an organized enclosure around the hydrophobic tail $[6]$.

Dendrimer is nano-sized, radially symmetric molecules with well-defined, similar, and monodisperse structures [7]. Dendrimer is tremendously branched, spherical and multivalent molecules with artificial elasticity and several probable usages extending from catalysis to electronics and drug discharge [8]. The size of this nanoparticle is effortlessly managed by the number of productions [6]. 
Liposomes are spherical vesicles containing phospholipid bilayers. They are formed from cholesterol and natural phospholipids. Because of their size, hydrophobic, and hydrophilic nature, they are encouraging systems for drug delivery. Their properties vary significantly with the composition of phospholipids, surface charge, size, and the mode of preparation [9]. The most common are unilamellar (having a single layer). The main advantages of liposomes are that they are totally recyclable, compatible, non-toxic, and nonimmunogenic [6].

Nanospheres are the particles with a size range between 10-200 $\mathrm{nm}$ in diameter. They are amorphous (shapeless). It has been revealed that the hydrophobic areas of these particles are extremely vulnerable to the action of phagocytes by the use of opsonin [10]. Sometimes, it is adsorbed at the surface of the nanoparticles or liquefied or trapped in the nanoparticle (nanosphere) or covered in a capsule like form inside a polymeric shell (nanocapsule) [6].

Nanocapsule is made up of a shell and a space in which preferred substances may be placed in. Nanocapsules are made from phospholipid molecules, which are hydrophobic on one end and hydrophilic on the other end, and when such molecules are placed in an aqueous environment, they can form capsules spontaneously, where the hydrophobic portions are inside, protecting them from water contact [11].

Fullerene comprises of carbon molecules with numerous extremely symmetric and stable. The most popular fullerene is the inflexible icosahedrons (a polyhedron with 20 faces) with 60 carbon atoms (C60). They are said to be three-dimensional analogs of benzene [12]. Fullerenes are highly strong molecules, able to resist high pressures [13].

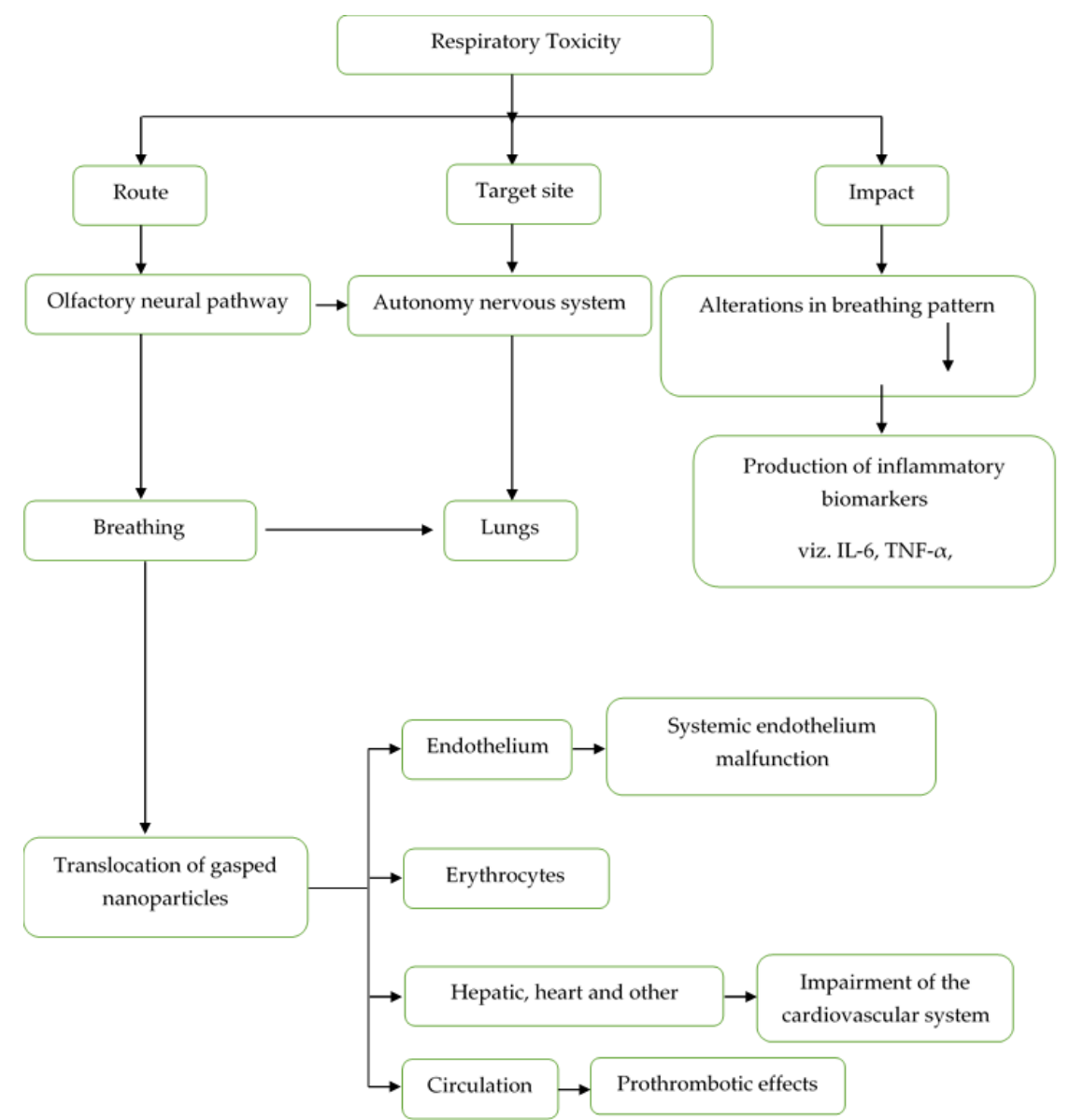

Figure 1. Schematic diagram of the main system impacts relevant to nanoparticles treatment and probable mechanism linked to those effects. 
Quantum dots are semi-conductors. They are tiny devices that contain tiny droplets of small electrons [14]. They are also referred to as nanometer-sized crystals [15]. Quantum dots are nanometric multifunctional inorganic fluorophores [6].

Inorganic molecules, for example, Au (gold), Ag (silver), Pt (platinum), and silica, may be employed to generate nanoparticles. Inorganic nanoparticles are synthesized through numerous methods, creating an extremely organized and unbending three-dimensional structure [6].

\section{Green synthesis of nanoparticles}

Green synthesis could be referred to as "green chemistry". This is said to be the plan of chemical products and processes to decrease or eradicate the use and the generation of hazardous/ dangerous substances [16]. This green synthesis involves the biological methods; this consists of synthesis using plants, synthesis using enzymes and biomolecules, synthesis using agricultural and industrial waste products, using microorganisms, and using algae [17].

\subsection{Green synthesis of nanoparticles using plants and plant extracts.}

Plant green synthesis of nanoparticles is a green synthesis method that attaches nanotechnology with plants. New methods of perfectly synthesizing nanoparticles are therefore formed at atmospheric temperatures, neutral $\mathrm{pH}$, less expensive, and environmentally friendly manner. Amid the biological options, medicinal plant extracts seem to be the best alternative. They are cost-efficient and require low maintenance [18]. In the synthesis of nanoparticles, the usage of a capping agent is involved. Capping agents are a rudimentary constituent employed in the synthesis of metal nanoparticles. Certainly, capping agent may also perform as a "poison", restraining availability of target sites, in addition to a "promoter", generating enhanced yields and unforeseen selectivity control [19]. The majority of the nanoparticles synthesized using plant and plant extracts are the metallic nanoparticles. Nanoparticles synthesized by various plants, as displayed in Table 1 .

Table 1. Different plants used in synthesizing nanoparticles.

\begin{tabular}{l|c|c} 
Plants & Nanoparticles & References \\
\hline Azadirachta indica & Silver $(\mathrm{Ag})$ and Gold $(\mathrm{Au})$ & {$[25]$} \\
\hline Aloe Vera & Gold $(\mathrm{Au})$ & {$[26]$} \\
\hline Hibiscus rosa sinensis & Silver $(\mathrm{Ag})$ & {$[27]$} \\
\hline Tridax procumbens & Silver $(\mathrm{Au})$ & {$[28]$} \\
\hline Szygium aromaticum & Silver $(\mathrm{Ag})$ and Gold $(\mathrm{Au})$ & {$[29]$} \\
\hline Talinum triangulare leaf aqueous extract & Silver $(\mathrm{Ag})$ & {$[30]$} \\
\hline Blighia sapida bark aqueous extract & Silver $(\mathrm{Ag})$ & {$[31]$} \\
\hline Gloriosa superbal & Copper $(\mathrm{Cu})$ & {$[32]$} \\
\hline Apple extract & Silver $(\mathrm{Ag})$ & {$[33]$} \\
\hline Ocimum sanctum & Platinum $(\mathrm{Pt})$ & {$[34]$} \\
\hline $\begin{array}{l}\text { Syzygium cumini polyphenolic-rich leaf } \\
\text { extracts }\end{array}$ & Silver $(\mathrm{Ag})$ & {$[35]$}
\end{tabular}

3.1.1. Green synthesis of gold nanoparticles via aloe vera extract.

Aloe vera is a cactus-like plant that cultivates freely in a hot and dry climate. The leaves are arranged in a rosette manner; they are triangular and spear-like and have thorny ridges. Aloe vera has been used for the anti-ulcer activity, wound healing, antioxidant activity, antibacterial and anti-viral activity, antiseptic, and traditionally used for wounds, burns, and skin irritations [20, 21]. Muralikrishna et al. [22] reported the reducing ability of aqueous extract from Aloe 
vera for the synthesis of gold nanoparticles. The formation of the nanoparticle was identified by the color change that occurred in the solution of $\mathrm{HAuCl}_{4}$ after the addition of plant extract. The color change observed was due to the property of quantum confinement. The synthesis of gold nanoparticles was achieved using a reagent tetrachloroauric acid ( $\mathrm{HAuCl} \bullet \mathrm{XH} \mathrm{O})$. Within a short time, alteration in color was noticed, showing nanoparticles synthesized. The monitoring of the reduction of $\mathrm{Au}^{3+}$ to nanoparticles characterization was via the $\mathrm{UV}$-vis spectrum.

\subsubsection{Synthesis of AgNPs via Talinum triangulare (Jacq.) willd. leaf extract.}

Ojo et al. [23] reported that the filtrate of Talinum triangulare was used as capping agent and stabilizer in $\mathrm{AgNO}_{3}$ nanoparticles synthesis. The appropriate quantity of Talinum triangulare leaf extract was measured into a conical flask. A suitable quantity of silver nitrate $\left(\mathrm{AgNO}_{3}\right)$ solution was also measured in a beaker and placed on a magnetic stirrer. The solution was completely mixed for around 15 minutes on the magnetic stirrer. A brown-yellow solution was formed from this, indicating the formation of silver nanoparticles attributable to the surface plasmon resonance phenomenon. Characterization was done using UV-VIS spectra analysis and Fourier transform infrared spectroscopy (FTIR) analysis.

3.1.3. Green synthesis of platinum nanoparticles (ptnps) from Ocimum sanctum (Tulsi) plantextracts.

Prabhu and Gajendran [24] reported the extract of Ocimum sanctum as a capping agent for the green biosynthesis of PtNPs from aqueous chloroplatinic acid $\left(\mathrm{H}_{2} \mathrm{PtC}_{16} \cdot 6 \mathrm{H}_{2} \mathrm{O}\right) .100 \mathrm{~mL}$ of $0.5 \mathrm{mM}, 1 \mathrm{mM}, 1.5 \mathrm{mM}$ and $2 \mathrm{mM}$ of metal solution of $\mathrm{H}_{2} \mathrm{PtC}_{16}$ was prepared. And the Ocimum sanctum extract was added. A magnetic stirrer was used in stirring $90 \mathrm{~mL}$ of $1 \mathrm{mM}$ $\mathrm{H}_{2} \mathrm{PtC}_{16} \cdot 6 \mathrm{H}_{2} \mathrm{O}$. The color changed to brown, this indicated bio-reduction of the ion. The nanoparticles synthesized were centrifuged for 15 minutes, after which lyophilization procedures were employed to obtain the powdered nanoparticles.

\subsubsection{Synthesis of copper nanoparticles (CuNPs) via Gloriosa superbal leaf extract.}

English names for Gloriosa superbal include flame lily, fire lily, etc. [25]. According to Pawar et al. [25], the green biosynthesis of CuNPs via extract of G. superbal was an adaptable method. In this synthesis, the source of $\mathrm{Cu}$ was $\mathrm{CuSO}_{4}$; the mixture of $80 \mathrm{~mL}$ of 1 $\mathrm{mM} \mathrm{CuSO}_{4}$ and $20 \mathrm{~mL}$ of $G$. superbal extract was added and allowed to stand for $24 \mathrm{hrs}$. After a short time, the color of the solution was transformed, which suggests copper nanoparticles development. It was followed up by the centrifugation of the solution for $15 \mathrm{~min}$ and disseminated in double distilled water to staunched unwanted materials. The mixture was characterized using UV visible spectroscopy.

\subsubsection{Green synthesis of AgNPs via apple extract.}

Ali et al. [26] used $\mathrm{AgNO}_{3}$ as a source of silver. The apple extract served as a capping agent. The green synthesis was done by using $20 \mathrm{~mL}$ of the apple extract in $180 \mathrm{~mL}$ of $0.1 \mathrm{M}$ aqueous $\mathrm{AgNO}_{3}$ solution. The solution was mixed and heated at $80^{\circ} \mathrm{C}$ for different durations. Characterization was achieved by means of UV-vis spectroscopy. This was to observed the color change of the solution. 
3.2. Green synthesis of nanoparticles using industrial and agricultural waste.

The use of industrial and agricultural wastes is another green approach used in synthesizing various nanoparticles. Some of these waste materials: Rice bran used in synthesizing gold nanoparticles, watermelon rind used in synthesizing palladium nanoparticles, industrial waste milk, grape skin, banana, tangerine peel (etc) used in synthesizing silver nanoparticles etc. [17].

\subsubsection{Watermelon rind-mediated green synthesis of noble palladium nanoparticles.}

Watermelon (Citrullus lanatus) is the biggest and weightiest fruit. The red part of the watermelon located interior is sweetened, eatable, and employed for juices and salads, but the outer rind is regarded as unwanted with no marketable worth. Watermelon rind comprises of pectin, citrulline, cellulose, proteins, and carotenoids, which are abundant in functional groups [27]. Lakshmipathy [28] used the aqueous extract from watermelon rind as a capping agent for green synthesis of palladium nanoparticles. Palladium chloride in distilled water was used as a source of palladium, and the synthesis was achieved when $20 \mathrm{~mL}$ of $1 \mathrm{mM} \mathrm{PdCl} 2$ solution was added with $10 \mathrm{~mL}$ of Watermelon rind extract and incubated at $150 \mathrm{rpm}$ for $24 \mathrm{~h}$. The formation of palladium nanoparticles was visually established.

3.2.2. Synthesis and characterization of AgNPs via banana peel extract.

According to Ibrahim [29], banana peel extract was used to biosynthesize AgNPs. The reaction solutions contained banana peel extract in $50 \mathrm{~mL}$ of silver nitrate solution $(1 \mathrm{mM})$. Variation of the $\mathrm{AgNO}_{3}$ concentration was used to assess the impact of the silver $(0.25,0.5$, $1.0,1.25,1.50,1.75$ or $2.0 \mathrm{mM})$. By regulating the biological $\mathrm{pH}$ of the mixtures, the influence was studied. Characterization was done using a UV-vis spectrophotometer.

\subsection{Green synthesis of nanoparticles using microbes/enzymes.}

The use of microorganisms for the production of nanomaterials is a promising approach, owing to the feasibility and cost-effectiveness of the process. Bacteria, actinomycetes, and fungi have been known for ages for their potential to purge out metals from their surroundings. The biological agents in the form of algae and microbes have come forth as an effective participant for the synthesis of nanoparticles [30].

\subsection{1. synthesis of gold nanoparticles using endophytic fungi.}

According to Ref. [31], the endophytic fungal cultures were used in the biosynthesis of AuNPs gotten from therapeutic plants. AgNPs were also effectively biosynthesized from these endophytic bacteria, revealing the property of the bio-reduction of metals. Aerobically, this endophytic bacterium was grown in liquid broth comprising malt extract powder, glucose, yeast extract, and peptone. The formation of AuNPs was originally detected by the color change from yellow to pink and established by the UV-Vis spectrum.

\subsubsection{Alpha-amylase mediated synthesis of AgNPs.}

According to Ref. [5], $\alpha$-amylase was the capping agent in this process. This synthesis involved incubation of $40 \mathrm{~mL}$ of $\alpha$-amylase solution and newly ready $60 \mathrm{~mL}$ of an aqueous 
solution of $\mathrm{AgNO}_{3}(1 \mathrm{mM})$. The biosynthesis of AgNPs was observed via UV-VIS spectroscopy.

\subsection{Limiting factors of the biosynthesis of nanoparticles.}

There are numerous limiting features of the green biosynthesis of nanoparticles. Some prevalent factors are:

3.4.1. The particular type of procedure used.

There are several protocols for biosynthesizing nanoparticles-each method with its exact benefits and shortcoming. Nevertheless, biological protocol employed in nanoparticles synthesis utilizes non-toxic, ecologically kind resources which work hand in hand. Hence, ecological are adequate to traditional protocols $[32,33]$.

\subsubsection{Temperature.}

Temperature is one major factor in the synthesis of nanoparticles. Here all three procedures used in synthesizing nanoparticles relies on this. Synthesis using the physical protocol involves the maximum temperature of greater than $623.15 \mathrm{~K}$, although the chemical approach needs a lesser amount of $623.15 \mathrm{~K}$. Often times nanoparticles needs temperatures less than $100{ }^{\circ} \mathrm{C}[34]$.

\subsection{3. $\mathrm{pH}$.}

$\mathrm{pH}$ is a vital aspect that affects nanoparticles synthesis. It has been revealed by researchers that $\mathrm{pH}$ affects the dimensions and quality of biosynthesized nanoparticles [35]. Thus, modifying the solution results in regulating the particular size of a nanoparticles.

\subsubsection{Size of the pores.}

The excellence and use of nanoparticles are significantly affected by the permeability of biosynthesized particles [36].

\subsubsection{Pressure.}

The pressure is significant in nanoparticles biosynthesis. The shape and structure of the biosynthesized nanoparticles are affected by pressure applied to the reaction [37]. The speed at which ions are reduced via organic agents was more rapid at room temperature [38].

\subsubsection{Time.}

Green synthesis, value, and form of the particle were significantly affected by the length of time the reaction medium is incubated [39]. The differences in the time may possibly ensue in countless manners for instance particles aggregation because of extended storage of time [40].

\subsubsection{Shape and size of particle.}

Particle size performs a vital function in evaluating nanoparticles properties [41]. Nanoparticles with comparable energy result in alteration of their shape, having different 
configurations [42]. The stimulation in the change of the shape of the nanoparticles is brought about by energy type frequently employed all through nanoparticles analyses [40].

\subsubsection{Proximity.}

Modification in the properties of particles is mostly observed when particles are in contact with the surface of other particles [43]. The observed character of the nanoparticles is involved in creating more tuned nanoparticles. However, the proximity property of nanoparticles has consequences like magnetic potentials of the particles [44].

\subsubsection{Preparation cost.}

In other to expedite the possible application of nanoparticles, the costs related to their synthesis requires total control. So, the cost of the generating procedure is a key factor that affects the synthesis of nanoparticles. The cost of the chemical method of synthesizing nanoparticles is less expensive and result in high yield in a short space of time. However, biological synthesis cost less but can be achieved on a large scale [44].

\subsubsection{Environment.}

The environment is a key factor in assessing the nature of biosynthesize nanoparticles. In an environment, a single nanoparticles can easily result in a core-shell by responding to several resources available from the environs by corrosion or by absorbing materials [45]. Hence, biosynthesized nanoparticles are thicker as a result of the coating formed in a biological system [46].

\subsubsection{Other factors.}

Medicinal plants are rich sources of secondary metabolites [47] that act as reducing agents for nanoparticles synthesis. Hence, the components of these phytochemicals depend on the nature and parts of the plant, as well as the protocol employed in its preparation [48]. In a like manner, diverse microorganisms produce remarkably different intracellular and extracellular enzymes in variable amounts that influence its synthesis [49]. Besides, the synthesized nanoparticles' quantity and quality can be swayed by the preference of procedures employed in purifying it. In several circumstances, the centrifugation protocol is employed in the separation of the particles [50]. Moreover, chromatography techniques are also employed in separating nanoparticles [51]. Hence, exhaustive separation of biosynthesized nanoparticles is accomplished by one or more protocol, followed by electrophoresis or chromatography [52]. The separation of nanoparticles is also key in their use both in the pharmaceutical and biomedical activities [53].

\section{Characterization of Synthesized Nanoparticles}

Characterization is achieved by determining the surface area and permeability, pore size, size dispersal, accumulation, surface analysis, adsorption properties, the communicating surface, crystalline, and morphology of nanoparticles.

Numerous procedures are employed to evaluate nanoparticle for example: Ultraviolet- (UV) visible spectroscopy, Transmission electron microscopy (TEM), Scanning electron microscopy 
(SEM), Dynamic light scattering (DLS), X-ray photoelectron spectroscopy (XPS), Fourier transform infrared spectroscopy (FT-IR) [54].

\subsection{The specificity of some characterization techniques.}

Few of the significant characterization methods intended to determine parameters are;

\subsubsection{Extraction analysis.}

Cloud point extraction is the biochemical process taken to achieved nanoparticles preparation. Low concentrations of nanoparticles need enhancement protocol before its critical assessment that can be derived by the addition [55].

4.1.2. Morphology and particle size determination.

The greatest important parameters for characterizing nanoparticles are morphology and particle size distribution [56].

\subsection{Characterization techniques.}

\subsubsection{Ultraviolent- visible spectroscopy.}

To confirm the formation, UV-visible spectroscopy was used to determine the countless kinds of nanoparticles by quantifying plasmon resonance and assessing the combined oscillations [57]. Information regarding the nature of the size, its structure, and stability, is provided by this [58]. Metal nanoparticles are related to precise absorption [59].

\subsubsection{TEM (Transmission electron microscopy).}

Transmission electron microscopy is one of the major employed procedures. It is used in the estimation of the shape, size, and structure of nanoparticles [60]. Though, the preparation of the sample is multifaceted and ultra-thin for transmittance. Hence, by reducing the quantity of the sample in solution and removing the additional solution with paper, thin films containing samples are prepared [56]. The particles are exposed to a monochromatic that infiltrates the sample and is projected onto a viewing screen to generate an image [61].

\subsubsection{SEM (Scanning electron microscopy).}

Scanning electron microscopy is utilized characterizing the morphology of nanoparticles via direct visual depiction. This procedure depends on electron microscopy and provides numerous merits for size analyses; however, it is related to numerous limitations, including the capability to offer few suggestions regarding the size distribution [56].

\section{Biomedical applications of nanoparticles}

Nanoscience and nanotechnologies are extensively seen as having huge possibilities to bring profits to many areas of research and application such as medicine, agriculture, and energy. In the following section, the biomedical applications of nanoparticles are emphasized. 


\subsection{Medicine.}

The application of nanoparticles in medicine is known as Nanomedicine. Nanomedicine involves drug and gene delivery, protein detection, diabetes treatment, tissue engineering, probing of DNA structure, tumor disinfection, and cancer therapy [62].

\subsubsection{Diabetes treatment.}

Diabetes has been a major threat to the health of individuals, which involves the inability of the $\beta$-cell of the pancreas to produce enough insulin for glucose regulation or the body cells not being able to make use of this insulin that is being produced. Insulin, a polypeptide made of 51 amino acids, has usually been administered parenterally in the management of diabetes mellitus. Unfortunately, the use of injections is painful, and most of the patients don't comply. Insulin can be administered orally, but it has shortcomings, as it is a protein and would be digested before being absorbed into the bloodstream [63]. However, the intestinal epithelium is the main obstacle for the absorption of drugs because of their inability to pass through epithelial cells into the circulatory system [64]. Due to this concern, it was said to improve the paracellular movement of drugs [65]. Several substances to enable permeability into the intestinal comprising chitosan are used for the support of the absorption macromolecules [66, 67]. Chitosan nanoparticles have improved the absorption of protein molecules to a larger extent in vivo. Chitosan nanoparticles are used for insulin delivery because of its reduced solubility at $\mathrm{pH}$ more than 6.5 (Fig. 2) [68].

\subsubsection{Cancer therapy.}

One of the major cause of mortatlity is cancer, and its prevalence continues to be on the rise. Of the management options for cancer are limited to chemotherapy, radiation, and surgery. Major challenges faced by recent cancer therapies are a nonspecific systemic distribution of anti-tumor agents, inadequate concentration of drugs getting to the tumor, and inadequate ability to monitor therapeutic response. Poor drug delivery leads to a lot of complications, including a multidrug resistance. The application of nanoparticles towards cancer management is based on certain characteristics [69]. The modulation of the surface properties and other physicochemical properties of nanoparticles might be useful in the growth of valuable systems [70]. Aiming the cancer cells happens through two dissimilar schemes: inactive and active targeting $[71,72]$. The inactive site of tumor cells by nanoparticles hangs upon an EPR effect [73]. This delivery depends on nanoparticle's half-time [74]. Hence, the aim choice is based on its great quantity [75]. Although it is said to be active, aiming might be the probable approach of polymeric nanoparticles to bring chemotherapeutic drugs to cancer cells [76].

\subsubsection{Treatment of neurodegenerative diseases.}

The application of nanotechnology in the treatment of neurodegenerative disorders, is very important [77]. For drug delivery of central nervous system therapeutics, several nanocarriers such as dendrimers, liposomes, are extensively researched.

\subsubsection{Parkinson's disease.}

The mechanism explained above, thus improve current therapeutic options for Parkinson's disease (PD). Parkinson's disease (PD) is the most common neurodegenerative 
disease after Alzheimer's. Parkinson's is a disorder of the cognitive function; that involves neuroinflammatory responses, which results in great complications with body motions.

\subsubsection{Alzheimer's disease.}

More than 35 million individuals are implicated by Alzheimer's disease (AD) worldwide, the main form of dementia. Nanotechnology discover important applications in neurology. These strategies are dependent on initial diagnosis and management of the disorders, which is made probable via scheming and manufacturing of a quantity of nanoparticulate entities [78].

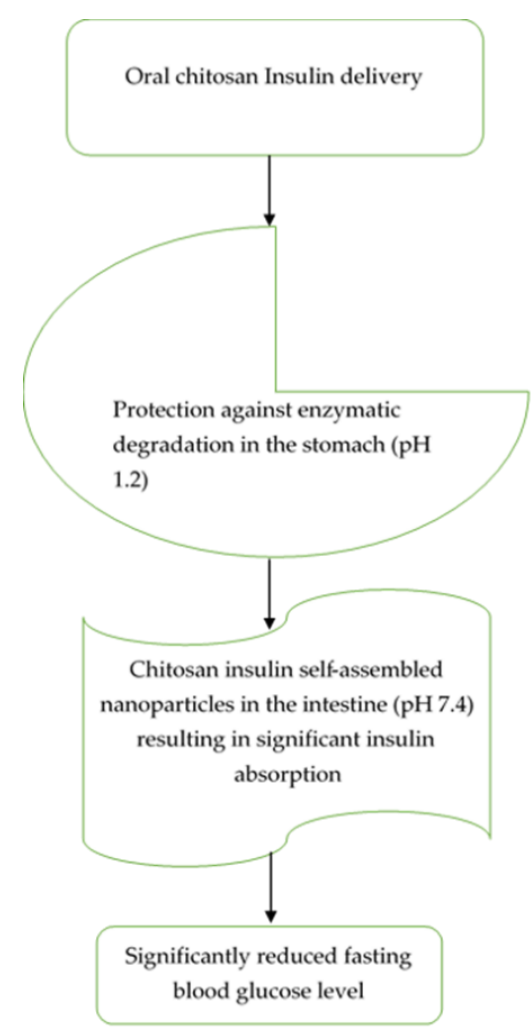

Figure 2. Schematic diagram of how chitosan nanoparticles are used in insulin delivery in diabetes treatment.

5.1.4. Drug delivery system for peptides and proteins.

The importance of protein delivery in the area of research increases as the amount of potential new biomolecules of biotechnological origin, for example, monoclonal antibodies, hormones, and vaccines, in addition to their beneficial potential increases $[79,80]$.

\subsubsection{Drug delivery for tuberculosis.}

Tuberculosis is a lethal infectious disease. The treatment involved with this disease takes a while, and the pill burden can encumber patient lifestyle and result in the development of multidrug resistant strains. Due to the size and versatility of the nanoparticles, drug administration has advantages over standard techniques [81]. The size of the nanoparticles permits for elevated transcytosis in the gut lumen's M cells enabled intracellular uptake in the lining epithelium, and enhanced uptake [82, 83]. Other applications of nanoparticles in medicine include; probing of DNA, bio-detection and gene pathogens, and phagoknetic studies etc [84]. 


\section{Conclusions}

The green chemistry approach for nanoparticles synthesis, is a valued substitute to both physical and chemical methods because it is eco-friendly, affordable, safe, and a nonnanotoxicological process. Hence, it interests more experts to fo for further developments and applications in the area of biomedical, thus, making this technique potentially stimulating for the large-scale synthesis of nanoparticle-based products.

\section{Funding}

This research received no external funding.

\section{Acknowledgments}

This research has no acknowledgment.

\section{Conflicts of Interest}

The authors declare no conflict of interest.

\section{References}

1. Parveen, K.; Banse, V.; Ledwani, L. Green synthesis of nanoparticles: Their advantages and disadvantages. AIP Conference Proceedings 2016, 1724, https://doi.org/10.1063/1.4945168.

2. Ahmed, H.B.; Abdel-Mohsen, A.M.; Emam, H.E. Green-assisted tool for nanogold synthesis based on alginate as a biological macromolecule. $R S C$ Adv 2016, 6, 73974-73985, https://doi.org/10.1039/C6RA16794B.

3. Nair, R.; Varghese, S.H.; Nair, B.G.; Maekawa, T.; Yoshida, Y.; Sakthi Kumar D. Nanoparticulate Material Delivery to Plants. Plant Science 2010, 179, 154-163, https://doi.org/10.1016/j.plantsci.2010.04.012.

4. Dey Bhowmik, A.; Bandyopadhyay, A.; Chattopadhyay, A. Cytotoxic and mutagenic effects of green silver nanoparticles in cancer and normal cells: a brief review. The Nucleus 2019, 62, 277-285, https://doi.org/10.1007/s13237-019-00293-0.

5. Mishra, A.; Sardar, M. Alpha-Amylase Mediated Synthesis of Silver Nanoparticles. Science of Advanced Materials 2012, 4, 143-146, https://doi.org/10.1166/sam.2012.1263.

6. Das, A.; Kamle, M.; Bharti, A.; Kumar, P. Nanotechnology and it's applications in environmental remediation: an overview. Vegetos 2019, 32, 227-237, https://doi.org/10.1007/s42535-019-00040-5.

7. Abbasi, E.; Aval, F.; Akbarzadeh, A.; Muani, M.; Nasrabadi, T.; Joo, W.; Hanifehpour, Y.; Nejati-Koshki K.; Pashaei-Asl, R. Dendrimers: synthesis, applications and properties. Nanoscale research letter 2014, 9 , https://dx.doi.org/10.1186\%2F1556-276X-9-247.

8. Karpagavinayagam, P.; Vedhi. C. Green synthesis of iron oxide nanoparticles using Avicennia marina flower extract. Vacuum 2019, 160, 286-292, https://doi.org/10.1016/j.vacuum.2018.11.043.

9. Akbarzadehl, A.; Rezaei-Sadabady, R.; Davaran, S.; Joo, W.; Zarghami, N.; Hanifehpour, Y.; Samiei, M.; Kouhi, M.; Nejati-Koshki, K. Liposomes: classification, preparations and applications. Nanoscale Research Letters 2013, 8, https://dx.doi.org/10.1186\%2F1556-276X-8-102.

10. Walia, S.; Acharya, A. Nanomaterials for Chemical and Biological Analyte Detection. J. Bionanosci. 2018, 12, 316-327.

11. Naumih, N. Green synthesis: Characterization and application of silver and gold nanoparticles. 2019; pp. 111-135.

12. Amini, S. Preparation of antimicrobial metallic nanoparticles with bioactive compounds. Materials Science and Engineering: C 2019, 103, https://doi.org/10.1016/j.msec.2019.109809.

13. Ulloa, E. Fullerenes and their applications in science and technology. Introduction to nanotechnology 2013.

14. Ghosh, S.; Ghosh, S.; Atta, A,K.; Pramanik, N. A succinct overview of hydroxyapatite based nanocomposite biomaterials: Fabrications, physicochemical properties and some relevant biomedical applications. $J$. Bionanosci 2018, 12, 143-158, https://doi.org/10.1166/jbns.2018.1515.

15. Vorobyova, V.I.; Skiba, M.I.; Shakun, A.S.; Nahirniak, S.V. Relationship between the inhibition and antioxidant properties of the plant and biomass wastes extracts - a review. Int J Corrosion Scale Inhibition 2019, 8, 150-178, http://dx.doi.org/10.17675/2305-6894-2019-8-2-1. 
16. Khandelwal, N.; Singh, A.; Jain, D.; Upadhyay, M.K.; Verma, H.N. Green synthesis of silver nanoparticles using Argimone mexicana leaf extract and evaluation of their antiomicrobial activities. J Nanomater Biostrct 2010, 5, 483-9.

17. Kora, A.J.; Sashidhar, R.B.; Arunachalam, J. Gum kondagogu (Cochlospermum gossypium), a template for the green synthesis and stabilization of silver nanoparticles with antibacterial application. J Carbohydr Polym 2010, 82, 670-9, https://doi.org/10.1016/j.carbpol.2010.05.034.

18. Buzea, C.; Pacheco, I.; Robbie, K. Nanomaterials and nanoparticles: Sources and toxicity. Biointerphase 2007, 2, 17-71.

19. Campisi, S.; Schiavoni, M.; Chan-Thaw, C.; Villa, A. Untangling the Role of the Capping Agent in Nanocatalysis: Recent Advances and Perspectives. Catalysts 2016, 6, 185.

20. Raksha, B.; Pooja, S.; Babu, S. Bioactive Compounds and Medicinal Properties of Aloe Vera L.: An Update. Journal of Plant Sciences 2014, 2, 102-107, https://doi.org/10.11648/j.jps.20140203.11.

21. Sanghi, S. Aloe vera: A medicinal herb. International journal of research- Granthaalayah 2015, 3, 32-34.

22. Muralikrishna, T.; Pattanayak, M.; Nayak, P. Green Synthesis of Gold Nanoparticles Using (ALOE VERA) Aqueous Extract. World Journal of Nano Science \& Technology 2014, 3, 45-51.

23. Ojo, O.A.; Oyinloye, B.E.; Ojo, A.B.; Afolabi, O.B.; Peters, O.A.; Olaiya, O.; Fadaka, A.; Jonathan, J.; Osunlana, O. Green Synthesis of Silver Nanoparticles (AgNPs) Using Talinum triangulare (Jacq.) Willd. Leaf Extract and Monitoring Their Antimicrobial Activity. Journal of Bionanoscience 2017a, 11, 292-296, https://doi.org/10.1166/jbns.2017.1452.

24. Prabhu, N.; Gajendran, T. Green Synthesis of Noble Metal of Platinum Nanoparticles from Ocimum sanctum (Tulsi) Plant- Extracts. Journal of Biotechnology and Biochemistry 2017, 3, 107-112, https://doi.org/10.9790/264X-0301107112.

25. Rajak, B.; Kumar, R.; Gogoi, M.; Patra, S. Antimicrobial Activity of Nanomaterials. Nanosci Med 2020, 1, 147-185.

26. Ali, Z.; Yahya, R.; Sekaran, S.; Puteh, R. Green Synthesis of Silver Nanoparticles Using Apple Extract and Its Antibacterial Properties. Advances in Materials Science and Engineering 2015, 1-6.

27. Rimandoa, M.; Perkins-Veazie, M. Determination of Citrulline in Watermelon Rind. J Chromatogr A 2005, 1078, 196-200, https://doi.org/10.1016/j.chroma.2005.05.009.

28. Lakshmipathy, R.; Palakshi, B.; Sarada, N.; Chidambaram, K.; Khadeer, P. Watermelon rind-mediated green synthesis of noble palladium nanoparticles: Catalytic application. Appl Nanosci 2015, 5, 223-228, https://doi.org/10.1007/s13204-014-0309-2.

29. Ibrahim, H. Green synthesis and characterization of silver nanoparticles using banana peel extract and their antimicrobial activity against representative microorganisms. J Rad Res. Appl. Sci 2015, 8, 265-275, https://doi.org/10.1016/j.jrras.2015.01.007.

30. Mohamed Saleem, A.; Prabhavathi, G.; Karunanithy, M.; Ayeshamariam, A.; Jayachandran, M. Green Synthesis of Nanoparticle by Plant Extracts-A New Aproach in Nanoscience. J. Bionanosci. 2018, 12, 401-407.

31. Nachiyar, V.; Sunkar, S.; Prakash, P.; Bavanilatha, S. Biological synthesis of gold nanoparticles using endophytic fungi. Der Pharma Chemica 2015, 7, 31-38.

32. Kharissova, O.; Dias, H.; Kharisov, B.; Perez, B.; Perez, V. The greener synthesis of nanoparticles. Trends in Biotechnology 2013, 31, 240-248, https://doi.org/10.1016/j.tibtech.2013.01.003.

33. Vadlapudi, V.; Kaladhar, D. Review: Green synthesis of silver and gold nanoparticles. Middle-East Journal of Scientific Research 2014, 19, 834-842.

34. Rai, A.; Singh, A.; Ahmad, A.; Sastry, M. Role of Halide Ions and Temperature on the Morphology of Biologically Synthesized Gold Nanotriangles. Langmuir 2006, 22, 736-741, https://doi.org/10.1021/la052055q.

35. Skiba, M.; Pivovarov, A.; Makarova, A.; Vorobyova, V. Plasmochemical preparation of silver nanoparticles: thermodynamics and kinetics analysis of the process. Eastern-Euro J Enterprise Technol 2018, 2, 4-9, https://dx.doi.org/10.15587/1729-4061.2018.127103.

36. Kishen, S.; Mehta, A.; Gupta, R. Biosynthesis and Applications of Metal Nanomaterials. Green Nanomaterials 2020, 139-157, https://doi.org/10.1007/978-981-15-3560-4_6.

37. Abhilash, B.; Pandey, B. Synthesis of zinc based nanomaterials: a biological perspective. IET Nanobiotechnology 2012, 6, 144-148, https://doi.org/10.1049/iet-nbt.2011.0051.

38. Barzinjy, A.; Hamad, S.; Aydın, S.; Ahmed, M.; Hussain. F. Green and eco-friendly synthesis of Nickel oxide nanoparticles and its photocatalytic activity for methyl orange degradation. Journal of Materials Science: Materials in Electronics 2020, 31, 11303-11316, https://doi.org/10.1007/s10854-020-03679-y.

39. Darroudi, M.; Ahmad, M.; Zamiri, R.; Zak, A.; Abdullah, A.; Ibrahim, N. Time-dependent effect in green synthesis of silver nanoparticles. International Journal of Nanomedicine 2011, 6, 677-68, https://doi.org/10.2147/ijn.s17669.

40. Abdullahi, M.B.; Rajaei, K.; Junin, R.; Bayat, A.E. Appraising the impact of metal-oxide nanoparticles on rheological properties of HPAM in different electrolyte solutions for enhanced oil recovery. J Pet Sci Eng 2019, 172, 1057-1068, https://doi.org/10.1016/j.petrol.2018.09.013. 
41. Akbari, B.; Tavandashti, M.; Zandrahimi, M. Particle size characterization of nanoparticles-a practicalapproach. Iranian Journal of Materials Science and Engineering 2011, 8, 48-56.

42. Kapoor, A.; Shankar, P.; Ali, W. Green Synthesis of Metal Nanoparticles for Electronic Textiles. Green Nanomaterials 2020, 81-97.

43. Shafaei, A.; Khayati, G. A predictive model on size of silver nanoparticles prepared by green synthesis method using hybrid artificial neural network-particle swarm optimization algorithm. Measurement 2020, 151, https://doi.org/10.1016/j.measurement.2019.107199.

44. Patra, K.; Baek, K. Green Nanobiotechnology: Factors Affecting Synthesis and Characterization Techniques. Journal of Nanomaterials 2014, 2014, 1-12, https://doi.org/10.1155/2014/417305.

45. Sarathy, V.; Tratnyek, P.; Nurmi, J. Aging of iron nanoparticles in aqueous solution: effects on structure and reactivity. The Journal of Physical Chemistry C, 2008, 112, 2286-2293, https://doi.org/10.1021/jp0777418.

46. Shaalan, M.; Saleh, M.; El-Mahdy, M.; El-Matbouli, M. Recent progress in applications of nanoparticles in fish medicine: a review Nanomed. Nanotechnol. Biol. Med 2016, 12, 701-710, https://doi.org/10.1016/j.nano.2015.11.005.

47. Ojo, O.A.; Ojo, A.B.; Ajiboye, B.O.; Oyinloye, B.E.; Imiere, O.; Adeyonu, O. Ameliorative potentials of Blighia sapida K.D. Koenig bark against pancreatic-cell dysfunction in alloxan-induced diabetic rats. Journal of complementary and Integrative medicine 2017b, 14, https://doi.org/10.1515/jcim-2016-0145.

48. Ojo, O.A.; Ojo, A.B.; Ajiboye, B.O.; Olaiya, O.; Akawa, A.; Olaoye, O.; Anifowose, O.; Idowu, O.; Olasehinde, O.; Obafemi, T.; Awe, J.; Oyinloye, B.E. Inhibitory effect of Bryophyllum pinnatum (Lam.) Oken leaf extract and their fractions on $\alpha$-amylase, $\alpha$-glucosidase and cholinesterase enzyme. Pharmacognosy Journal 2018a, 10, 497-506.

49. Mousavi, B.; Tafvizi, F.; Bostanabad, S. Green synthesis of silver nanoparticles using Artemisia turcomanica leaf extract and the study of anti-cancer effect and apoptosis induction on gastric cancer cell line (AGS). Artificial Cells, Nanomedicine, and Biotechnology 2018, 46, 499-510, https://doi.org/10.1080/21691401.2018.1430697.

50. Sharma, G.; Pandey, S.; Ghatak, S.; Watal, G.; Rai, P. Potential of Spectroscopic Techniques in the Characterization of "Green Nanomaterials". In: Nanomaterials in Plants, Algae, and Microorganisms. 2018; pp. 59-77, https://doi.org/10.1016/B978-0-12-811487-2.00003-7.

51. Daphedar, A.; Taranath. T. Characterization and cytotoxic effect of biogenic silver nanoparticles on mitotic chromosomes of Drimia polyantha (Blatt. \& McCann) Stearn. Toxicology Reports 2018, 5, 910-918.

52. Govindh, B.; Diwakar, B.; Reddy, V.; Srikanth, V.; Kumar, K.; Ramam, K.; Swaminadham. V. Structural, photocatalytic and optical applications of biologically synthesized silver nanoparticles. Materials Today: Proceedings 2018, 5, 25823-25831, https://doi.org/10.1016/j.matpr.2018.06.575.

53. Kowalczyk, B.; Lagzi, I.; Grzybowski, B. Nanoseparations: strategies for size and/or shape-selective purification of nanoparticles. Current Opinion in Colloid and Interface Science 2011, 16, 135-148, https://doi.org/10.1016/j.cocis.2011.01.004.

54. Gupta, V.; Gupta, A.; Kant, V. Synthesis, characterization and biomedical application of nanoparticles. Science International 2013, 1, 167-174, http://dx.doi.org/10.5567/sciintl.2013.167.174.

55. Abdel-Shafy, H.; Mansour, M. Green Synthesis of Metallic Nanoparticles from Natural Resources and Food Waste and Their Environmental Application 2018; $\quad$ pp. 321-385, https://doi.org/10.1002/9781119418900.ch11.

56. Jorge de Souza, T.A.; Rosa Souza, L.R.; Franchi, L.P. Silver nanoparticles: an integrated view of green synthesis methods, transformation in the environment, and toxicity. Ecotoxicol Environmental Safety 2019, 171, 691-700, https://doi.org/10.1016/j.ecoenv.2018.12.095.

57. Deshmukh, S.P.; Patil, S.M.; Mullani, S.B.; Delekar, S.D. Silver nanoparticles as an effective disinfectant: a review. Materials Science and Engineering: $C$ 2019, 97, 954-965, https://doi.org/10.1016/j.msec.2018.12.102.

58. Ojo, O,A.; Oyinloye, B.E.; Ojo, A.B.; Ajiboye, B.O.; Olayide, I.; Idowu, O.; Olasehinde, O.; Fadugba, A.; Adewunmi, F. Green-route mediated synthesis of silver nanoparticles (AgNPs) from Syzygium cumini (L.) Skeels polyphenolic-rich leaf extracts and investigation of their antimicrobial activity. IET Nanobiotechnology 2018b, 12, 305-310, https://doi.org/10.1049/iet-nbt.2017.0127.

59. Zhang, X.F.; Liu, Z.G.; Shen, W.; Gurunathan, S. Silver nanoparticles: synthesis, characterization, properties, applications, and therapeutic approaches. Int J Mol Sci, 2016, 17, https://doi.org/10.3390/ijms17091534.

60. Ojo, A.B.; Ojo, O.A.; Oyinloye, B.E.; Ajiboye, B.O.; Osukoya, O.A.; Ogunniran, A.O.; Fadugba, A.; Olasehinde, O.; Idowu, O.; Koenig, K.D. Characterization and Biological Activities of Biosynthesized Silver Nanoparticles from Stems of Blighia sapida Journal of Bionanoscience 2018c, 12, 71-75, https://doi.org/10.1166/jbns.2018.1497.

61. Tarannum, N.; Divya, K.; Gautam, Y. Facile green synthesis and applications of silver nanoparticles: a stateof-the-art review. RSC Adv. 2019, 9, 34926-34948, https://doi.org/10.1039/C9RA04164H.

62. Li, M.; Luo, Z.; Peng, Z.; Cai, K. Cascade-amplification of therapeutic efficacy: an emerging opportunity in cancer treatment. Wiley Interdisciplinary Reviews: Nanomedicine and Nanobiotechnology 2019, 11, https://doi.org/10.1002/wnan.1555. 
63. Kesharwani, P.; Gorain, B.; Low, S.Y.; Tan, S.A.; Ling, E.C.S.; Lim, Y.K.; Chin, C.M.; Lee, P.Y.; Lee, C.M.; Ooi, C.H.; Choudhury, H.; Pandey, M. Nanotechnology based approaches for anti-diabetic drugs delivery. Diabetes Res. Clin. Pract. 2018, 136, 52-77, https://doi.org/10.1016/j.diabres.2017.11.018.

64. Patra, J.K.; Das, G.; Fraceto, L.F.; Campos, E.V.R.; Rodriguez-Torres, M.D.P.; Acosta-Torres, L.S.; DiazTorres, L.A.; Grillo, R.; Swamy, M.K.; Sharma, S.; Habtemariam, S.; Shin, H.S. Nano based drug delivery systems: Recent developments and future prospects. J. Nanobiotechnol. 2018, 16, https://doi.org/10.1186/s12951-018-0392-8.

65. Ghorbani, A.; Rashidi, R.; Shafiee-Nick, R. Flavonoids for preserving pancreatic beta cell survival and function: A mechanistic review. Biomed. Pharmacother. 2019, 111, 947-957, https://doi.org/10.1016/j.biopha.2018.12.127.

66. Shi, G.J.; Li, Y.; Cao, Q.H.;Wu, H.X.; Tang, X.Y.; Gao, X.H.; Yu, J.Q.; Chen, Z.; Yang, Y. In vitro and in vivo evidence that quercetin protects against diabetes and its complications: A systematic review of the literature. Biomed. Pharmacother. 2019, 109, 1085-1099, https://doi.org/10.1016/j.biopha.2018.10.130.

67. Khurana, R.K.; Bansal, A.K.; Beg, S.; Burrow, A.J.; Katare, O.P.; Singh, K.K.; Singh, B. Enhancing biopharmaceutical attributes of phospholipid complex-loaded nanostructured lipidic carriers of mangiferin: Systematic development, characterization and evaluation. Int. J. Pharm. 2017, 518, 289-306, https://doi.org/10.1016/j.ijpharm.2016.12.044.

68. Paul, D.; Manna, K.; Sengupta, A.; Mukherjee, S.; Dey, S.; Bag, P.K.; Dhar, P. A novel nanoformulation of $\alpha$-eleostearic acid restores molecular pathogenesis of hypersensitivity. Nanomedicine (Lond.) 2019, 14, 529552.

69. Mi, Y.; Hagan IV, C.T.; Vincent, B.G.; Wang, A.Z. Emerging nano-/microapproaches for cancer immunotherapy. Advanced Science 2019, 6, https://doi.org/10.1002/advs.201801847.

70. Kunjachan, S.; Jose, S.; Lammers, T. Understanding the mechanism of ionic gelation for synthesis of chitosan nanoparticles using qualitative techniques. Asian J Pharm 2014, 4, 72-76.

71. Sambi, M.; Bagheri, L.; Szewczuk, M.R. Current challenges in cancer immunotherapy: multimodal approaches to improve efficacy and patient response rates. $J$ Oncol 2019, https://doi.org/10.1155/2019/4508794.

72. Park, W.; Heo, Y.J.; Han, D.K. New opportunities for nanoparticles in cancer immunotherapy. Biomaterials Res 2018, 22, https://dx.doi.org/10.1186\%2Fs40824-018-0133-y.

73. Dimitriou, N.M.; Pavlopoulou, A.; Tremi, I.; Kouloulias, V.; Tsigaridas, G.; Georgakilas, A.G. Prediction of gold nanoparticle and microwave-induced hyperthermia effects on tumor control via a simulation approach. Nanomaterials 2019, 9, https://doi.org/10.3390/nano9020167.

74. Jo, S.D.; Nam, G.H.; Kwak, G.; Yang, Y.; Kwon, I.C. Harnessing designed nanoparticles: Current strategies and future perspectives in cancer immunotherapy. Nano Today 2017, 17, 23-37, https://doi.org/10.1016/j.nantod.2017.10.008.

75. Yoon, H.Y.; Selvan, S.T.; Yang Y.; Kim, M.J.; Yi, D.K.; Kwon, I.C.; Kim, K. Engineering nanoparticle strategies for effective cancer immunotherapy. Biomaterials 2018, 178, 597-607, https://doi.org/10.1016/j.biomaterials.2018.03.036.

76. Xie, J. Gong, L.; Zhu, S.; Yong, Y.; Gu, Z.; Zhao, Y. Emerging strategies of nanomaterial-mediated tumor radiosensitization. Advanced Materials 2018, 31, https://doi.org/10.1002/adma.201802244.

77. Khan, I.; Saeed, K.; Khan, I. Nanoparticles: properties, applications and toxicities. Arab. J. Chem. 2019, 12, 908-931, https://doi.org/10.1016/j.arabjc.2017.05.011.

78. Kim, H.; Lee, J.U.; Song, S.; Kim, S.; Sim, S.J. A shape-code nanoplasmonic biosensor for multiplex detection of Alzheimer's disease biomarkers. Biosens Bioelectron. 2018, 101, 96-102, https://doi.org/10.1016/j.bios.2017.10.018.

79. Kumar, J.; Eraña, H.; López-Martínez, E. L.; Claes, N.; Martín, V.F.; Solís, D.M.; Bals, S.; Cortajarenaa, A.L.; Castilla, J.;Liz-Marzán, L.M. Detection of amyloid fibrils in Parkinson's disease using plasmonic chirality. PNAS 2018, 115, 3225-3230, https://doi.org/10.1073/pnas.1721690115.

80. Pan, C.T.; Chang, W.H.; Kumar, A.; Singh, S.P.; Kaushik, A.C.; Sharma, J.; Long, Z.J.; Wen, Z.H.; Mishra, S.M.; Yen, C.K.; Chaudhary, R.K.; Shiue, Y-L. Nanoparticles-mediated brain imaging and disease prognosis by conventional as well as modern modal imaging techniques: a comparison. Curr. Pharm. Design 2019, 25, 2637-2649, https://doi.org/10.2174/1381612825666190709220139.

81. Shanmuganathan, R.; Karuppusamy, I.; Saravanan, M.; Muthukumar, H.; Ponnuchamy, K.; Pugazhendhi, V.S.R. Synthesis of silver nanoparticles and their biomedical applications - a comprehensive review. Current Pharmaceut Design 2019, https://doi.org/10.2174/1381612825666190708185506.

82. Montelongo-Peralta, L.Z.; León-Buitimea, A.; Palma-Nicolás, J.P.; Gonzalez-Christen, J.; MoronesRamírez, J.R. Antibacterial activity of combinatorial treatments composed of transition-metal/antibiotics against Mycobacterium tuberculosis. Sci Rep 2019, 9, 1-6, https://doi.org/10.1038/s41598-019-42049-5.

83. Yuan, D.; He, H.; Wu, Y.; Fan, J.; Cao, Y. Physiologically based pharmacokinetic modeling of nanoparticles. J Pharm Sci. 2019, 108, 58-72, https://doi.org/10.1016/j.xphs.2018.10.037.

84. Geetanjali, S.; Sharma, P.K.; Malviya, R. Toxicity and application of nano-silver in multi-drug resistant therapy. Letters in Applied NanoBioScience, 2020, 9, 824 - 829. 